Original Research Paper

\title{
Effect of Distance of the Submerged Vanes from the Outer Bank on Sediment Movement within $180^{\circ}$ Bend
}

\author{
Jaafar S. Maatooq and Barq A. Adhab \\ Building and Construction Engineering, University of Technology, Baghdad, Iraq
}

\author{
Article history \\ Received: 08-06-2017 \\ Revised: 23-06-2017 \\ Accepted: 03-07-2017 \\ Corresponding Author: \\ Jaafar S. Maatooq \\ Building and Construction \\ Engineering, University of \\ Technology, Baghdad, Iraq \\ Email: 40071@uotechnology.edu.iq
}

\begin{abstract}
A small aspect ratio of submerged vanes when used near the outer bank at the angle of attack between $10^{\circ}$ to $20^{\circ}$ and at the initial height above the bed between $20-40 \%$ of flow depth is considered one of the most successful river training structures. Vanes when located within the bends of river, produces helical swirls at inverse action with the centrifugally secondary current action. Accordingly, its existence leads to mitigate the influence of the secondary current, thus reducing the outer bank erosion. The present study aims to investigate the effect of distance which measured from the outer bank $(\delta b)$ on the hydraulic performance of vanes when it arranged at a specified configuration within $180^{\circ}$ bend. As a result, when the submerged vanes have been installed at $\delta \mathrm{b} / \mathrm{b}=0.25$ within the third to the fifth sectors of bend and $\delta b / b=0.1$ within the sixth sector at a zigzag pattern led to lesser outer bank scour with the Percentage Improvement (PIindicator) equal to $72.71 \%$.
\end{abstract}

Keywords: Submerged Vanes, River Bend, Scour, Outer Bank, Meandering, Secondary Flow

\section{Introduction}

In river reaches when flow passes through bends or meanders, the secondary current developed due to the combination of both transverse pressure gradient and centrifugal force. The outer bank of bend reach become subjected to the scour due to a high velocity component near the surface, while the low velocity component created near bed has the influence to transport the scoured particles from the outer bank towards the inner bank thus causes the deposition, this mechanism was stated by Odgaard and kennedy (1983; Odgaard and Spoljaric, 1986; Odgaard and Wang, 1991a; Marelius and Sinha, 1998; Voisin and Townsend, 2002) and many others before and thereafter. Different techniques have been used in practice to prevent or mitigate the action of this problem at river bends includes construction the dikes and revetments. A major difficulty with these techniques is the lack of analytical tools for predicting their effectiveness and impact on the channel. Another technique consists of installing a small aspect ratio of submerged vanes on stream bed at $10^{\circ}-30^{\circ}$ angles of attack with the mean flow to counter the secondary current action. This technique was introduced by
Odgaard and Kennedy (1983) for the first time to control the scour at the outer bank. The vortices are created at the location of vane and extend downstream, then its strength decay gradually due to the streamwise velocity. The low helical action created by the vortices causes transverse shear stress on the river bed which lead the sediment to transport transversely but opposite the direction effect of secondary current, thereby it will mitigate the scour and deposition at both outer and inner banks respectively. The effect of vanes on scour and sediment control has tested by many researchers; Voisin and Townsend (2002) introduced the best dimensions of submerged vanes to protect the outer river banks in bend sections. Coonrod et al. (2010) constructed a physical model of the Reo Grand River to investigate the effect of submerged vanes to control sediment movement within bends. The characteristics of the flow and sediment motion around the vanes by using laboratory model were studied by Tan et al. (2005). However, the study of Odgaard and Wang (1991b) was investigated the effect of vane location from the outer bank, the study shows that the efficient location depends on the initial vane height " $H$ " above the bed and by using multiple arrays. The study 
concluded that the best arrangement of vanes were at; the aspect ratio $\mathrm{H} / \mathrm{L}=0.3$, the angle of attack $\alpha=20^{\circ}$ and the vane spacing $\delta \mathrm{n}=3 \mathrm{H}$, while the streamwise spacing $\delta$ s between vans was ranged between 15 and $30 \mathrm{H}$. It should mention that the authors does not refer to the impact of the distance of vane measured from the outer bank $(\delta b)$ on sediment movement along and across the bend reach.

In present study the effect of vanes distance from the outer bank " $\delta b$ " has been focused on sediments movement both for scour feature at outer bank and shoal's amelioration near the inner bank. This distance was tested at different values with different vans configurations. The well performance indicators are a less outer bank scour along with nearly horizontal transverse bed slope. Thin plat vanes were installed at one, two and three rows in the zigzag patterns within $180^{\circ}$ bend to achieve these two aims.

\section{The Experimental Flume}

The experimental flume at the hydraulic laboratory of Building and Construction Engineering Department, UOT-Baghdad, $60 \mathrm{~cm}$ in width and $20 \mathrm{~cm}$ in depth was used. The flume consist of three sections; the straight section $1.5 \mathrm{~m}$ long followed by $180^{\circ}$-bend section as a working reach then a third straight section as a downstream reach its length is $2 \mathrm{~m}$ connected with a trap basin and tail gate to facilitate trap the sand and regulate the depth of flow, Fig. 1 illustrate the plane sketch of flume with more details in geometric and dimensions of all parts. The $8.5 \mathrm{~cm}$ thickness of uniform graded sand with the average partial size $\mathrm{d} 50=$ $0.327 \mathrm{~mm}$ and standard deviation $\sigma \mathrm{g}=1.3$ has been used to cover the entire bottom of the flume. The $2 \mathrm{~mm}$ thickness galvanized plates are manufactured at $3 \mathrm{~cm}$ in length to simulate the vanes. Just $0.9 \mathrm{~cm}$ of each van is protruding above the initial plan bed to simulate the height of vane " $H$ ". These vanes are fixed to configure the different arrangement and tested to achieve the purposes of this study.

\section{Flow Conditions}

The intensity of flow should be suitable to satisfy the clear water flow condition at the approach section of the flume, whereas at the bend sections it help to access a maximum bank scour. Different attempts have been made as trials to get this goal. The final trial of these attempts has been stabilized to use flow depth at the approach section equal $3 \mathrm{~cm}$ and the discharge $218.559 \mathrm{l} / \mathrm{min}\left(0.003643 \mathrm{~m}^{3} / \mathrm{s}\right)$ to give the depth average velocity, $\mathrm{V}=0.2024 \mathrm{~m} / \mathrm{s}$ and Froude number 0.373 , where this value of Froude number is at a consistent with the context of the flow usual in the rivers. According to this flow condition the critical depth average velocity $\mathrm{Vc}=0.1955 \mathrm{~m} / \mathrm{s}$ is calculated based on equation which proposed by Melville and Sutherland (1988) for clear water flow. This flow condition is appropriate to achieve the study aim among numerous trials. Therefore, the working intensity in all experiments undertaken is $\mathrm{V} / \mathrm{Vc}=$ 1.035; this intensity causes the bed material to be at a threshold movement in approach section of the flume.

\section{Submerged Vane Configurations and Specification}

The submerged vanes have been installed at an angle of attack with the flow direction $\alpha=15^{\circ}$ and the aspect ratio $\mathrm{H} / \mathrm{L}=0.3$. The test was conducted for three different configurations as detailed in Table 1 and shown in Fig. 2, whereas, Fig. 3 shows the determinants of the installation of vanes $\delta \mathrm{b}, \delta \mathrm{s}$ and $\delta \mathrm{n}$.

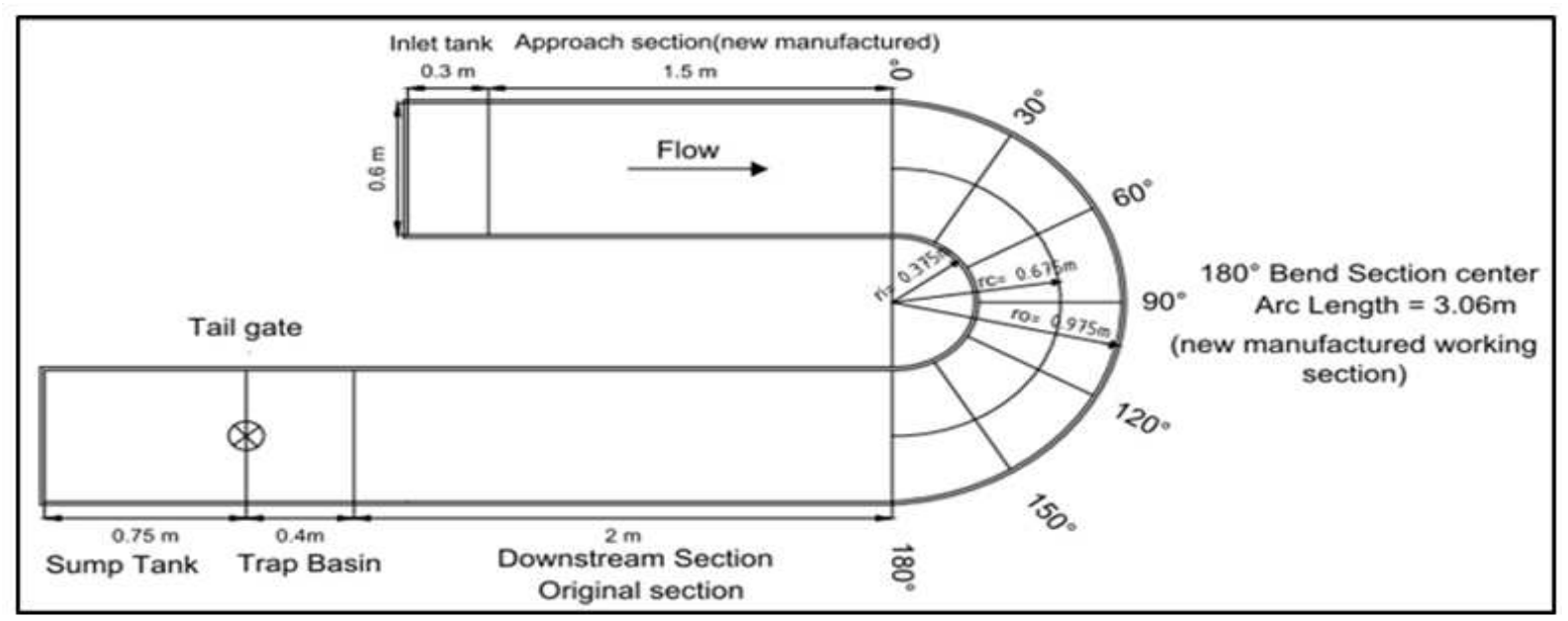

Fig. 1. Plane sketch of flume sections with necessary dimension 

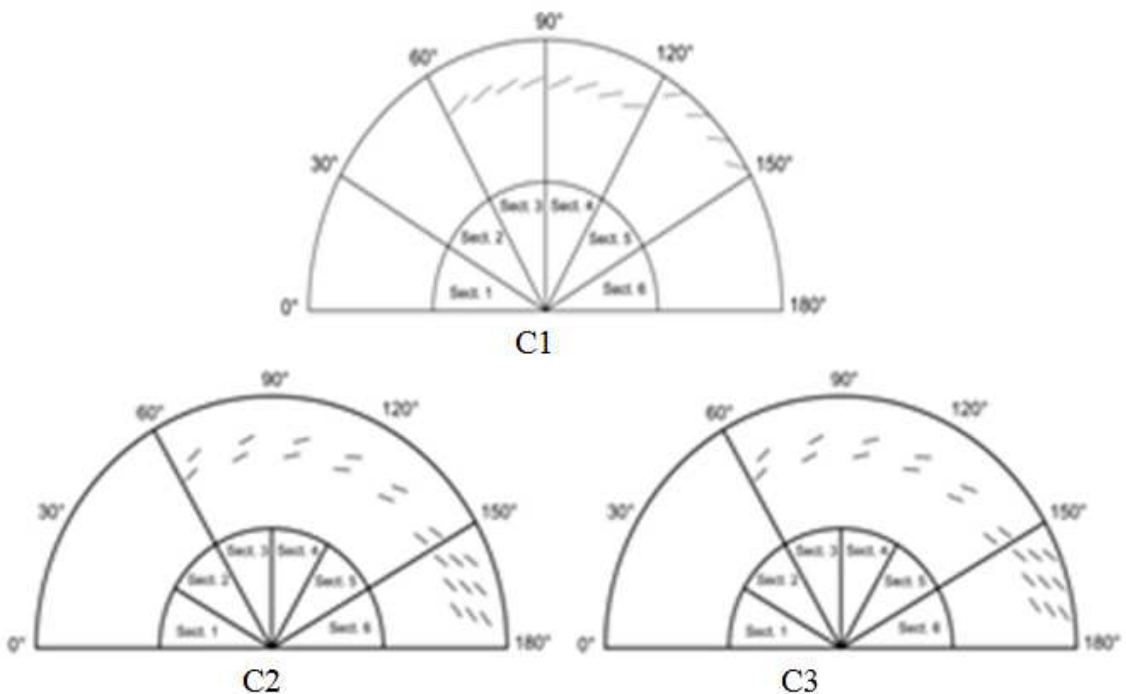

(a)

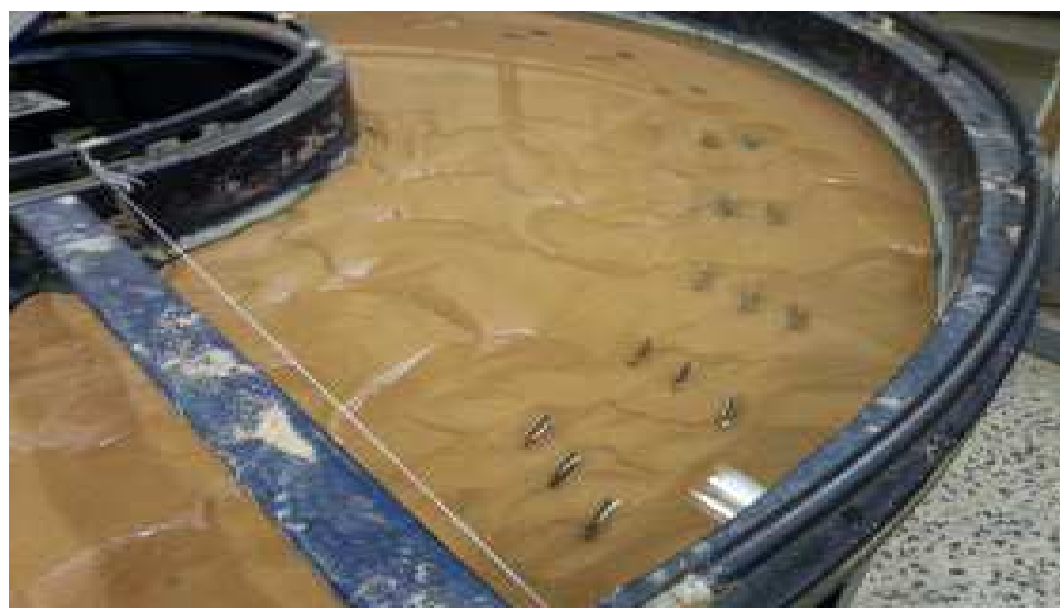

(b)

Fig. 2. Vanes installations for $180^{\circ}$ bend; (a) the sketches of configurations undertaken (b) illustration of bed morphology with $\mathrm{C} 3$ after end of run

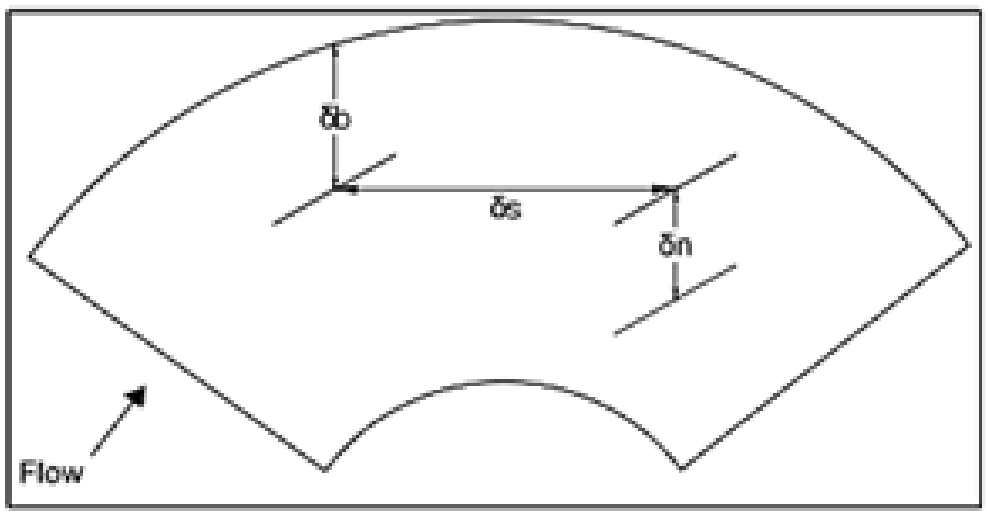

Fig. 3. Definitions indicates the vane location 
Table 1. Vanes configurations details of arrangement

\begin{tabular}{ll}
\hline Config. No. & Details of arrangement \\
\hline C1 & 8-vanes at single row installed at $\delta_{\mathrm{b}} / \mathrm{b}=0.25$ and $\delta_{\mathrm{s}} / \mathrm{b}=0.14$ in third to fourth \\
& sectors. 4-vanes installed at $\delta_{\mathrm{b}} / \mathrm{b}=0$ and $\delta_{\mathrm{s}} / \mathrm{b}=0.17$ in the sixth sector. Where \\
& $\mathrm{b}$ is the width of bend reach. \\
& 12 -vanes at two rows each row consisting 6-vanes installed at $\delta_{\mathrm{b}} / \mathrm{b}=0.25, \delta_{\mathrm{s}} / \mathrm{b}=0.35$, \\
$\mathrm{C} 2$ & $\delta_{\mathrm{n}} / \mathrm{b}=0.075$ within a third to fifth sectors at zigzag pattern. 9-vanes at three rows each \\
& row consisting 3 -vanes allocated $\delta_{\mathrm{b}} / \mathrm{b}=0.175, \delta_{\mathrm{s}} / \mathrm{b}=0.25, \delta_{\mathrm{n}} / \mathrm{b}=0.075$ at zigzag pattern. \\
& 12 -vanes at two rows 6 -vanes for each row installed as a zigzag pattern at $\delta_{\mathrm{b}} / \mathrm{b}=0.25$, \\
$\mathrm{C} 3$ & $\delta_{\mathrm{s}} / \mathrm{b}=0.35, \delta_{\mathrm{n}} / \mathrm{b}=0.075$ within the third to fifth sectors. 9-vanes installed as a zigzag pattern \\
& at three rows, 3-vanes for each row located at $\delta_{\mathrm{b}} / \mathrm{b}=0.1, \delta_{\mathrm{s}} / \mathrm{b}=0.26, \delta_{\mathrm{n}} / \mathrm{b}=0.075$ \\
& installed at the last sector. \\
\hline
\end{tabular}

\section{Duration of Test}

A preliminary test has been done without vanes installation to find more realistic equilibrium time. Bed form elevations are measured transversely at each sector angle for different time intervals of operation by using a point gauge after shutdown and dewatering. These measurements aim to get the maximum scour at the outer bank and the lateral steepest slope for each sector when adopting various times for runs. The results of this procedure are as can appear in all affected sectors which located between $\theta$ $=60^{\circ}-180^{\circ}$ refers to the more change in bed form, particularly at outer bank, was recorded after four hours period of operation. Also through the visual observations it could point out that, the change in the bed form within the bend was just started after the second hour of operation and became approximately constant and stabilized when the operation continued up to $4 \mathrm{~h}$. The records for the longest time of operation thereafter shows not change significantly for both the bed form and elevations. Thus based on these results the equilibrium time was adopted to occur after $4 \mathrm{hrs}$ for all models undertaken.

\section{Improvement Percentage (\% PI)}

The perfect vane performance is its ability to prevent or mitigate the outer bank scour. This performance can be accomplished through encountering the action of the secondary current that it will assist in the fixity of the outer bank. As a result, this performance may prevent or reduce the movement of sediment from the outer bank to the inner bank (in the present work, lowering the average scour depth at the outer bank). One of the most indicators adopting to achieve this performance is "Improvement Percentage" was firstly submitted by (Voisin and Townsend, 2002) as:

$$
\% P I=\left[\frac{d_{w v}-d_{v}}{d_{w v}}\right] * 100
$$

In which $\left(d_{w v}\right)$ is the average scour depth at the outer bank without using vanes (plane bed) and $\left(d_{v}\right)$ is the average scour depth at the outer bank when vane adopted at a specified configuration on the bed within the bend reach. The $P I=100 \%$, indicating the zero scour at the outer bank. While the $0 \%$ of this indicator refer to that the installation of vane does not have any effect on scouring process (i.e., $d_{v}=d_{w v}$ ).

\section{Transverse Bed Slope (ST)}

Another indicator of improvement is when the transverse bed slope of bend ST become nearly horizontal (i.e., $\mathrm{ST}=0$ ). The increases in ST refer to more erosion at the outer bank and more deposition (shoal) at the inner bank. Thus a decreasing in transverse slope ensures less outer bank erosion beside shoal's amelioration. After run stopped and completely dewatering the bed levels collected at each $3 \mathrm{~cm}$ transversely for each sector. A linear trend line between these points is considered as the transverse bed slope ST (Table 3). This procedure was also previously used by Voisin and Townsend (2002).

\section{Results}

As mentioned previously, all experiments have been intended to show the influence of vane lateral distance location from the outer bank, $\delta b$ on \% PI and ST indicators. The results of analysis are listed in Table 2 based on PI indicator which produced that, the best location of the vane was with $\mathrm{C} 3$. However, Table 3 shows the average transverse slope ST for bend without vanes and its value when using vans at a specified configuration. The results refer that the less $\mathrm{ST}=0.0268$ was also recorded with $\mathrm{C} 3$, as this value is the closest from horizontal. Figure 4 illustrate that the near horizontal slope ST was achieved with $\mathrm{C} 3$ in which $\delta \mathrm{b} / \mathrm{b}=0.25$ within the third to the fifth sector and $\delta b / b=0.1$ within the sixth sector at a zigzag pattern. 
Table 2. Summary of improvement percentage for vane configurations

\begin{tabular}{lc}
\hline Vane configurations & Improvement \%PI \\
\hline C1 & $68.46 \%$ \\
C2 & $55.39 \%$ \\
C3 & $72.71 \%$ \\
\hline
\end{tabular}

Table 3. ST after a specified installation of Vanes Configuration

\begin{tabular}{llll}
\hline Average Liner trend in sectors $(3-6)$ & $\mathrm{d}_{\mathrm{BF}}$ at $\mathrm{b}=0(\mathrm{~cm})$ & $\mathrm{d}_{\mathrm{BF}}$ at b $=60(\mathrm{~cm})$ & $\mathrm{S}_{\mathrm{T}}=\Delta \mathrm{d}_{\mathrm{BF}} / \mathrm{b}$ \\
\hline Average $\left(\mathrm{d}_{\mathrm{wv}}\right)$ without vanes & 5.2990 & 10.2850 & 0.0831 \\
Average $\left(\mathrm{d}_{\mathrm{v}}\right)$ with using C1 & 7.2602 & 10.1234 & 0.0477 \\
Average $\left(\mathrm{d}_{\mathrm{v}}\right)$ with using C2 & 7.0587 & 9.5871 & 0.0421 \\
Average $\left(\mathrm{d}_{\mathrm{v}}\right)$ with using C3 & 7.5784 & 9.1888 & 0.0268 \\
\hline
\end{tabular}

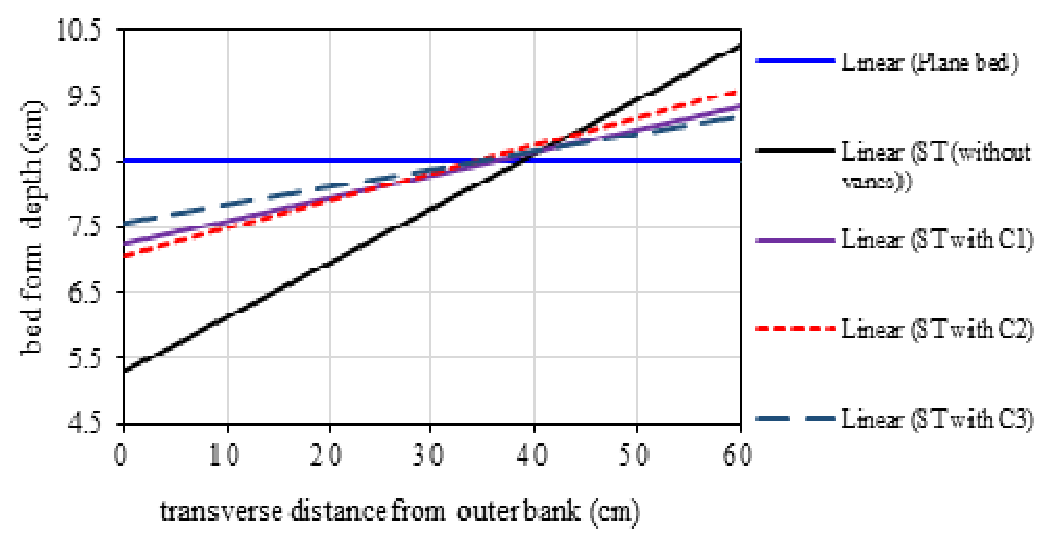

Fig. 4. Comparison of transverse bed slope without and with adopting vanes at different configurations

\section{Conclusion}

This study introduces a summary of the physical sample experimentation scheme to discover the vane performance in $180^{\circ}$ bend flume with attempt to use different $\delta b / b$ ratios. It was based on the application of selected standards to the results to find which of the distance of submerged vanes from the outer bank $\delta b$ has a benefit performance. These standards established on performance measures such as scour depth decreased along the outer bank (\% PI indicator) and the reduction of the transverse bed slope (ST) across the bend reach. The key limitation of this study was the distance of the submerged vanes $\delta b$ from the outer bank. The experimental results lead that $\delta b / b=0.25$ was best location of submerged vanes to give a high performance when it installed from the third to fifth sectors. While into sixth sector the vanes should installed at $\delta b / b=0.1$. This difference can be attribute to that the maximum velocity of flow was restricted near the end of the bend which needed a less distance between vanes and the outer bank to reduce the erosion.

\section{Notation}

The following symbols are used in this study:

$\mathrm{b} \quad=$ flume width
$\mathrm{C}=$ configuration

$\mathrm{d} 50=$ mean particle size of sand

$\mathrm{dBF}=$ Bed form depth at end of run

$\mathrm{dwv}=$ Bed scour depth at end of runs resulted at outer bank without vanes

$\mathrm{dv}=$ Bed scour depth at end of run when the vanes installed

$\mathrm{H}=$ Height of vane

$\mathrm{L}=$ Length of vane

PI = Improvement Percentage

ST = Transverse bed slope

$\mathrm{V}=$ Depth average velocity

$\mathrm{Vc}=$ Critical depth average velocity

$\delta \mathrm{b}=$ Distance from bank to vane

$\delta \mathrm{s}=$ Vane spacing in streamwise direction

$\delta \mathrm{n}=$ Vane spacing in transverse direction

$\sigma \mathrm{g}=$ Geometric standard deviation

$\alpha=$ vane angle of attack with stream direction

\section{Acknowledgment}

The authors grateful to the Water and Hydraulic Structures Branch-Hydraulic Laboratory for approval of the use flume and measurement facilities. Appreciation to the technician members of Hydraulic Laboratory for assistance in preparing models. Deeply acknowledge to Building and Construction Engineering the UOT/Baghdad for academic assistance. 


\section{Author's Contributions}

Jaafar S. Maatooq: Designed the research plan, the data-analysis and writing the manuscript.

Barq A. Adhab: Prepare the flume with measurement devices and facilities, models installation, and measurements.

\section{Ethics}

Any ethical issues that may arise after the publication of this manuscript are under the author responsibility.

\section{References}

Coonrod, J., T. Gill and M. Brent, 2010. Case study: Movable bed model scaling for bed load sediment exclusion at intake structure on Rio Grande. ASCE J. Hydraulic Eng., 136: 247-250.

DOI: 10.1061/(ASCE)HY.1943-7900.0000149

Marelius, F. and S.K. Sinha, 1998. Experimental investigation of flow past submerged vanes. J. Hydraulic Eng., 124:5: 542-545.

DOI: 10.1061/(ASCE)0733-9429(1998)124:3A5(542)

Melville, B.W. and A.J. Sutherland, 1988. Design method for local scour at bridge piers. J. Hydraulic Eng., 114: 1210-1226. DOI: 10.1061/(ASCE)07339429(1988)114:3A10(1210)
Odgaard, J.A. and A. Spoljaric, 1986. Sediment control by submerged vanes. ASCE J. Hydraulic Eng., 112: 1164-1181. DOI: 10.1061/(ASCE)07339429(1986)112:3A12(1164)

Odgaard, J.A. and C.E. Mosconi, 1987. Stream bank protection by submerged vanes. ASCE J. Hydraulic Eng., 113: 521-536. DOI: 10.1061/(ASCE)07339429(1987)113:3A4(520)

Odgaard, J.A. and Y. Wang, 1991a. Sediment management with submerged vanes (I): Theory. ASCE J. Hydraulic Eng., 117: 267-283. DOI: 10.1061/(ASCE)0733-9429(1991)117:3A3(267)

Odgaard, J.A. and Y. Wang, 1991b. Sediment management with submerged vanes. II: Applications. ASCE J. Hydraulic Eng., 117: 284-302. DOI: 10.1061/(ASCE)0733-9429(1991)117:3A3(284)

Tan, S.K., G. Yu, S.Y. Lim and M.C. Ong, 2005. Flow structure and sediment motion around submerged vanes in open channel. J. Waterway Port Coastal Ocean Eng., 131: 132-136.

DOI: 10.1061/(ASCE)0733-950X(2005)131:3(132)

Voisin, A. and R.D. Townsend, 2002. Model testing of submerged vanes in strongly curved narrow channel bends. Cand. J. Civil Eng., 29: 37-42.

DOI: $10.1139 / 101-078$ 